\title{
OLETA E RECICLAGEM DE RESÍDUOS SÓLIDOS URBANOS: CONTRIBUIÇÃO AO DEBATE DA SUSTENTABILIDADE AMBIENTAL
}

Recebido: $17 / 06 / 2019$

Aprovado: $10 / 01 / 2020$

\author{
Giovana Goretti Feijó de Almeida ${ }^{1}$ \\ Rosí Cristina Espindola da Silveira² \\ Vonia Engel ${ }^{3}$
}

\section{Resumo}

Objetivo: Refletir sobre a coleta seletiva dos resíduos sólidos urbanos e o que acarreta à sociedade o consumo desenfreado sem considerar o descarte dos produtos que ela própria consome.

Método: O método é um estudo de caso com pesquisa qualitativa, contemplando dados secundários do IBGE, PMGIRS, PERS e do SNIS. Aplicaram-se questionários à SMMASS; à Conesul e à COOMCAT.

Originalidade/Relevância: Centra-se nas discussões sobre a coleta seletiva com vistas à reciclagem de resíduos sólidos urbanos, em Santa Cruz do Sul-RS, pela perspectiva do desenvolvimento local e regional.

Resultados: A questão educacional-ambiental é igualmente uma estratégia de enfrentamento dos problemas relacionados à reciclagem dos resíduos sólidos urbanos. Embora haja leis aprovados desde 2010 somente a legislação vigente ainda é insuficiente. Falta interesse da sociedade no correto descarte dos resíduos urbanos o que revela indiferença com quem trabalha na reciclagem (catadores). É importante trabalhar com a qualidade de vida no intuito de promover o desenvolvimento local e regional.

Contribuições teóricas/metodológicas: O referencial teórico está estruturado a partir da abordagem sobre a política de planejamento no âmbito dos resíduos sólidos urbanos e as discussões sobre os estilos de vida e a educação ambiental a partir do consumo e do descarte dos resíduos sólidos urbanos. Ao final, apresenta-se o caso dos resíduos sólidos urbanos, em Santa Cruz do Sul-RS. Esta pesquisa discute ainda como a coleta seletiva e o processo de reciclagem de resíduos sólidos urbanos estão pautados no contexto das políticas de planejamento ambiental, no município de Santa Cruz do Sul-RS, no período de 2013 a 2016 , e a partir da vigência do Plano Municipal de Gestão Integrada de Resíduos Sólidos (PMGIRS).

Contribuições sociais / para a gestão: Ressalta-se a importância de trabalhar a conscientização ambiental na coleta seletiva de resíduos sólidos, juntamente com as questões socioambientais desde cedo, por meio de uma postura educacional, assim como o entendimento de que somos todos corresponsáveis pelo que a sociedade produz e descarta.

Palavras-chave: Resíduos sólidos. Planejamento ambiental. Desenvolvimento regional. Políticas públicas ambientais. Educação ambiental.

\section{Como Citar:}

Almeida, G., Silveira, R., \& Engel, V. (2020). Coleta e Reciclagem de Resíduos Sólidos Urbanos: Contribuição ao Debate da Sustentabilidade Ambiental. Future Studies Research Journal: Trends and Strategies [FSRJ], 12(2), 289-310. doi:https://doi.org/10.24023/FutureJournal/2175-5825/2020.v12i2.445

\footnotetext{
${ }^{1}$ Pontifícia Universidade Católica do Paraná - PUC, (Brasil). E-mail: goretti.giovana@gmail.com. Orcid id: https://orcid.org/0000-0003-0956-1341

Universidade em Santa Cruz do Sul, Rio Grande do Sul - UNISC, (Brasil). E-mail: rosi@unisc.br. Orcid id: http://orcid.org/0000-0001-9732-0550

${ }^{3}$ Faculdade América do Sul, em Novo Cabrais, (Brasil). E-mail: vonia engel@hotmail.com. Orcid id: http://orcid.org/0000-0002-3226-7629
} 


\title{
OLLECTION AND RECYCLING OF SOLID URBAN
} CONTRIBUTION TO DEBATE AMBIENTAL SUSTENTABILITY

WASTE:

\begin{abstract}
Purpose - To reflect on the selective collection of solid urban waste and what causes unrestrained consumption to society without considering the disposal of the products it consumes.
\end{abstract}

Theoretical framework - The theoretical framework is structured based on the approach to planning policy in the scope of urban solid waste and discussions on lifestyles and environmental education based on the consumption and disposal of urban solid waste. At the end, we present the case of solid urban waste, in Santa Cruz do Sul-RS. This research also discusses how the selective collection and the recycling process of solid urban waste are guided in the context of environmental planning policies, in the municipality of Santa Cruz do Sul-RS, in the period from 2013 to 2016, and from the term of the Municipal Plan for Integrated Solid Waste Management - PMGIRS.

Design/methodology/approach - The method is a case study with qualitative research, including secondary data from IBGE, PMGIRS, PERS and SNIS. Questionnaires were applied to SMMASS; Conesul and COOMCAT.

Findings - The educational-environmental issue is also a strategy to face the problems related to the recycling of solid urban waste. Although laws have been passed since 2010, only current legislation is still insufficient. Society lacks interest in the correct disposal of urban waste, which reveals indifference to those who work in recycling (waste pickers). It is important to work with quality of life in order to promote local and regional development.

Research, Practical \& Social implications - The importance of working with environmental awareness in the selective collection of solid waste, together with socio-environmental issues from an early age, through an educational stance, as well as the understanding that we are all co-responsible for what society produces and discards.

Originality/value - It focuses on discussions on selective collection with a view to recycling solid urban waste, in Santa Cruz do Sul-RS, from the perspective of local and regional development.

Keywords: Solid waste. Environmental planning. Regional development. Public environmental policies. Environmental education.

\section{How to cite the article:}

Almeida, G., Silveira, R., \& Engel, V. (2020). Collection and Recycling of Solid Urban Waste: Contribution to Debate Ambiental Sustentability. Future Studies Research Journal: Trends and Strategies, 12(2), 289-310. doi:https://doi.org/10.24023/FutureJournal/2175-5825/2020.v12i2.445 


\title{
Introdução
}

Cada vez mais a coleta seletiva de resíduos sólidos urbanos (RSU) tem sido tema para discussões quanto à preservação, conservação do meio ambiente e ao uso dos recursos naturais. "[...] Os resíduos sólidos são subprodutos das atividades humanas, provenientes das residências, comércios, indústrias, serviços de saúde, serviços públicos de varrição, capina e poda; construção civil e tecnologia" (PMSCS, 2013, p. 13). É um problema que diz respeito a todos os cidadãos e a toda a sociedade.

A Lei no 12.305/2010 institui a Política Nacional de Resíduos Sólidos (PNRS, 2010) e dispõe sobre instrumentos importantes que permitem "[...] o avanço necessário ao País no enfrentamento dos principais problemas ambientais, sociais e econômicos decorrentes do manejo inadequado dos resíduos sólidos" (MMA, 2017). Também trata sobre a prevenção e a redução na geração de resíduos por meio da prática de hábitos de consumo mais sustentáveis, bem como estabelece um conjunto de instrumentos que visam o aumento da reciclagem e da reutilização dos resíduos sólidos e a destinação ambientalmente adequada dos rejeitos (MMA, 2017). Aqui cabem abordar a distinção entre resíduos sólidos, rejeitos, reciclagem e coleta seletiva, pois, muitas vezes, esses termos são vistos e entendidos como sinônimos.

\begin{abstract}
Resíduos sólidos: material, substância, objeto ou bem descartado resultante de atividades humanas em sociedade, cuja destinação final se procede, se propõe proceder ou se está obrigado a proceder, nos estados sólido ou semissólido, bem como gases contidos em recipientes e líquidos cujas particularidades tornem inviável o seu lançamento na rede pública de esgotos ou em corpos d'água, ou exijam para isso soluções técnica ou economicamente inviável em face da melhor tecnologia disponível (PNRS, 2017).
\end{abstract}

Assim, os Resíduos Sólidos tem relação com aquilo que tem valor econômico e pode ser reciclado ou reaproveitado após o seu descarte.

Rejeitos: resíduos sólidos que, depois de esgotadas todas as possibilidades de tratamento e recuperação por processos tecnológicos disponíveis e economicamente viáveis, não apresentem outra possibilidade que não a disposição final ambientalmente adequada (PNRS, 2017).

Em outras palavras, os rejeitos são também um tipo de resíduo sólido, todavia não podem ser reciclados ou reutilizados posteriormente, ficando no descarte a única opção disponível. A reciclagem tem relação com o "[...] processo de transformação dos resíduos sólidos que envolvem a alteração de suas propriedades físicas, físicoquímicas ou biológicas, com vistas à transformação em insumos ou novos produtos [...]" (PNRS, 2010 [2017]). E a coleta seletiva diz respeito à "[...] coleta de resíduos sólidos previamente segregados conforme sua constituição ou composição" (PNRS, 2010). Desta forma, as nomenclaturas apresentadas, embora não possam ser 
consideradas expressões com sentido idêntico, tem em comum o descarte de bens materiais produzidos pela sociedade, variando no processo e no destino desses produtos.

A quantidade de lixo urbano produzido, bem como sua coleta tem relação com a saúde da população e com a proteção ao meio ambiente. Quando os resíduos não coletados são postos em locais inapropriados, especialmente a céu aberto, por exemplo, eles proporcionam um ambiente propício à geração de vetores causadores de várias doenças contagiosas (dengue, zicavírus, malária, leptospirose, entre outras), contaminando ainda o solo, o ar e a água. Sem o gerenciamento adequado e responsável desses resíduos haverá ainda maiores problemas sociais e ambientais. Sob este ponto de vista, percebe-se que é de fundamental importância a gestão correta dos resíduos sólidos para a preservação dos recursos naturais, solo, atmosfera e dos recursos hídricos. O impacto imediato causado pelo descaso no gerenciamento dos resíduos sólidos deriva do processo de urbanização e pode a curto e longo prazo comprometer o meio ambiente urbano e a qualidade de vida da população local. Para Mueller (2012) é necessário que se forme um consenso a respeito dos problemas ambientais, bem como encontrar instrumentos a serem usados para resolver esse problema.

A decomposição da matéria orgânica correspondente a mais de $40 \%$ da composição gravimétrica dos mesmos. O Instituto Brasileiro de Geografia e Estatística (IBGE, 2010) revelou que, nos últimos anos, a universalização da coleta de resíduos em áreas urbanas brasileiras aumentou significativamente, assim como as formas de descarte menos adequadas tem sido reduzidas consideravelmente, tanto nas áreas urbanas quanto nas rurais.

A mídia mostra que o Brasil tem aumentado gradativamente seu índice de reciclagem de resíduos sólidos. Prática que se mantém igualmente em outros países, não sendo mérito apenas do Brasil, mas uma tendência mundial. Essa preocupação com a reciclagem, gestão dos resíduos sólidos, coleta seletiva e descarte de rejeitos não ocorre somente por causa das questões ambientais, mas pela própria sobrevivência do planeta. Assim sendo, este artigo traz a reflexão sobre a coleta seletiva com vistas à reciclagem dos resíduos sólidos urbanos e a forma como o poder público local trabalha com essa questão na contemporaneidade nos contextos do desenvolvimento local e regional.

À vista do exposto, a questão-problema enfatiza: como a coleta seletiva e o processo de reciclagem de resíduos sólidos urbanos estão pautados no contexto das políticas de planejamento ambiental, no município de Santa Cruz do Sul-RS, no período 
de 2013 a 2016, e a partir da vigência do Plano Municipal de Gestão Integrada de Resíduos Sólidos (PMGIRS).

O objetivo é refletir sobre a coleta seletiva dos resíduos sólidos urbanos e o que acarreta à sociedade o consumo desenfreado sem considerar o descarte dos produtos que ela própria consome.

\section{Metodologia da Pesquisa}

O método adotado é o estudo de caso (Yin, 2015) sobre a realidade do município de Santa Cruz do Sul, RS, Brasil. É uma pesquisa qualitativa que emprega técnicas qualitativas de análise.

O estudo contemplou 5 fases: 1) discussão teórica; 2) coleta de dados secundários a partir do IBGE, PMGIRS, PERS e do SNIS, em 2016; 3) Entrevista por meio de questionários enviado por email à SMMASS, Conesul e COOMCAT; 4) aprofundamento do caso de Santa Cruz do Sul e; 5) análises de dados. Optou-se pelo município investigado a partir de critérios por conveniência das autoras terem maior acessibilidade aos dados para o estudo proposto. O critério dos dados secundários também foi devido ao acesso as informações públicas disponíveis. O referencial teórico está estruturado a partir da abordagem sobre a política de planejamento no âmbito dos resíduos sólidos urbanos e as discussões sobre os estilos de vida e a educação ambiental a partir do consumo e do descarte dos resíduos sólidos urbanos. Ao final, apresenta-se o caso dos resíduos sólidos urbanos, em Santa Cruz do Sul-RS. Esta pesquisa discute ainda como a coleta seletiva e o processo de reciclagem de resíduos sólidos urbanos estão pautados no contexto das políticas de planejamento ambiental, no município de Santa Cruz do Sul-RS, no período de 2013 a 2016, e a partir da vigência do Plano Municipal de Gestão Integrada de Resíduos Sólidos (PMGIRS).

Para tanto, os procedimentos metodológicos partem de uma pesquisa qualitativa, cunho exploratório, utilizando-se de pesquisa bibliográfica e documental. Esta última contemplou os dados secundários do IBGE, e do Sistema Nacional de Informações sobre Saneamento - SNIS - em relação ao destino dos resíduos sólidos urbanos. Também foi aplicado um questionário, enviado via e-mail, à Secretaria de Meio Ambiente de Santa Cruz do Sul, à Conesul Serviços Ambientais e à Cooperativa de Catadores e Recicladores de Santa Cruz do Sul (COOMCAT).

\section{A política de planejamento ambiental no contexto dos resíduos sólidos urbanos}

Várias discussões em relação às políticas públicas na reconfiguração do encadeamento entre desenvolvimento econômico e sustentabilidade ambiental no 
contexto local e regional vêm sendo colocadas em pauta. Segundo Peres e Chiquito (2012), há muitos embates e limites para que possa haver uma integração total entre as escalas territoriais, os instrumentos de planejamento, atores e instituições. As múltiplas políticas brasileiras criadas transformaram o território e geraram igualmente inúmeras situações de conflito. A dimensão ambiental - recursos naturais, patrimônio natural e cultural - como elemento de integração territorial trouxe novos recortes regionais como, por exemplo, as Unidades de Conservação e as Bacias Hidrográficas.

Esta questão evidenciou a necessidade de articulação e ação conjunta em âmbito regional, além do local, tamanha a sua importância social. Contudo, a apropriação do território (usos e acessos) em diversos períodos ao longo da história destacou interesses diversos, fragilizou e continua a fragilizar a natureza que tem sofrido transformações constantes e, muitas vezes, drásticas (Peres \& Chiquito, 2012; Giddens, 2010). Rissato, Santos e Nazzari (2010) analisaram as políticas públicas ambientais voltadas à gestão de resíduos sólidos urbanos no município de Cascavel, Santa Catarina, no período de 1990 a 2007. Encontraram que embora a gestão de resíduos sólidos urbanos tenha indícios de avanço ainda se faz necessário políticas públicas mais efetivas, bem como ações coordenadas envolvendo secretarias municipais do meio ambiente, do desenvolvimento e da ação social, da educação e da saúde. Silva e Biernaski (2018) avaliaram o planejamento e à gestão de resíduos sólidos urbanos da região metropolitana de Belo Horizonte, Brasil, e encontram ausência de variáveis no sistema de gerenciamento, mesmo havendo uma legislação vigente.

À vista do exposto, tornar-se essencial refletir sobre a forma como o território vem sendo apropriado, sobreposto e interligado, pois deste também deriva a relação homem-natureza e a sua própria sobrevivência (Novo, 1997). Neste enquadramento, um dos principais desafios da gestão pública é o de pensar o planejamento como um processo dinâmico que consiga articular os diferentes recortes territoriais na visão das políticas públicas. Esta complexidade de pensar e planejar o território também diz respeito às questões ambientais em múltiplas escalas e ao manejo, gerenciamento e gestão sobre dos resíduos sólidos urbanos.

A humanidade está enfrentando uma problemática ambiental séria que tem gerado uma realidade complexa e policêntrica, visto que seus atores agem de forma independente, inclusive discordando entre si (Novo, 1997; Peres \& Chiquito, 2012). Quando um projeto ambiental apresenta discordância entre seus atores, principalmente no nível micro, os demais níveis emergem na tentativa de resolver as tensões e os conflitos gerados (Ribeiro, 2012), ou mesmo de fortalecer uma das 
partes. Essa discordância tem como origem os valores e a forma como os atores percebem e interagem com a realidade a partir de seu ponto de vista e de seus interesses. Quando se vive em tempos de intolerância, essas diferenças podem ser preocupantes. Mas em tempos de democracia, ou melhor, de construção da democracia, essas diferenças se caracterizam como riqueza cultural em um mundo civilizado e altruísta.

Esses conflitos não resolvidos podem gerar uma crise ambiental e configurar diversos impasses: desajustes populacionais, desequilíbrios, difusão da sociedade de consumo, desenvolvimento da tecnologia sem avaliar seus impactos, fortes migrações, urbanização crescente, perda da biodiversidade, contaminação da água, perda de solos férteis, a feminilização da pobreza, enfim, a relação com o conjunto que acaba afetando as pessoas de forma geral (Novo, 1997). Todos esses problemas não surgem sozinhos, isoladamente; mas são resultados das relações sociais e econômicas e, principalmente, das interações entre as pessoas e o meio ambiente.

Novo (1997) salienta que o problema ambiental aborda ainda o alcance e o significado da crise, evidenciando a contextualização desses impasses que perpassam pela importância de mudanças de pensamento e na forma como o ser humano interage com o meio ambiente. Faz-se urgente entender que os recursos naturais são finitos e impõe limites ao seu uso, estabelecendo um novo ritmo de relações sociais e econômicas. Pensar novas formas de planejamento e gestão de recursos que tenham como diretriz principal a sustentabilidade ambiental é uma realidade que precisa ser enfrentada séria e urgente (Giddens, 2010). Os prazos urgem para as soluções ambientais. Há uma grande responsabilidade do governo, do Estado e do poder público local nessas questões para que se possa obter êxito em seus desfechos. No entanto, ressalta-se que não apenas as políticas públicas são responsáveis por esse contexto, mas a sociedade com um todo.

Giddens (2010) elencou nove tarefas nas quais o Estado precisa ser o ator principal (ou pelo menos deveria ser). São elas: ajudar a pensar com antecipação; lidar com os riscos da mudança climática e da energia, no contexto dos outros riscos enfrentados pela sociedade; promover a convergência política e econômica; fazer intervenções nos mercados para institucionalizar o princípio do poluidor-pagador; agir contra os interesses empresariais que visarem barrar as iniciativas ligadas à mudança climática; manter a mudança climática no topo da pauta de objetivos políticos; desenvolver uma estrutura econômica e fiscal apropriada; preparar-se para a adaptação às consequências das mudanças climáticas e integrar os aspectos multiescalares da política da mudança climática. Apesar disso, essa postura exigirá 
inovações no governo e nas relações entre Estado, mercado e a sociedade civil, já que planejar não é uma tarefa simples, ao contrário, é complexa e demanda o interesse de todos.

Torna-se importante para o poder público local entender o seu território e a região na qual está inserido, compreendendo e buscando soluções para seus problemas peculiares. O planejamento e a gestão ambiental precisam contemplar a própria imprevisibilidade do meio ambiente, assim como criar políticas de planejamento que busquem mudar as atitudes das pessoas em relação ao risco ambiental (Giddens, 2010). Deste modo, emerge a ideia de retroprevisão (que é diferente de previsão) que seria colocar na balança as futuras opções e objetivos das políticas adotadas, sugerindo inclusive inovações que possam contribuir na solução dos problemas ambientais e na forma como as pessoas estão vivendo.

Surgem novos estilos de vida que podem ser veiculados pela mídia e adotados pela sociedade. A educação ambiental, por exemplo, torna-se um importante fator (porém, não o único) a ser considerado para que se possa promover uma mudança significativa quanto à forma como a sociedade consome, descarta, recicla e trata seus resíduos. Assim, a complexidade das questões ambientais urbanas perpassa, inclusive, pela forma como as pessoas se relacionam com a coleta seletiva e a própria reciclagem dos produtos que consomem e, posteriormente, descartam. Essas ações se configuram como um desafio diante de "[...] uma predominância de considerações econômicas, no planejamento e nas tomadas de decisão mais globais relativas ao desenvolvimento das sociedades, o que tem implicado em sérios problemas tanto do ponto de vista social como ambiental" (Figueiredo, 1994, p.83). A grande questão está em como mudar o estilo de vida, "[...] considerando a aparente intratabilidade do sistema de extrair-produzir-descartar e as cruéis estatísticas, envolvendo o caos climático e a perda de recursos naturais" (Leonard, 2011, p.249). Nesse sentido, a política de planejamento ambiental precisa também contemplar situações do cotidiano das pessoas, como é o caso do manejo e gestão dos resíduos sólidos urbanos.

\section{Novos estilos de vida e educação ambiental: uma questão de cidadania}

Segundo dados do IBGE (2010, p. 176), o percentual de moradores em domicílios particulares permanentes, por tipo de destino de resíduo sólido urbano e situação do domicílio em todo o território brasileiro, em 2008 , foi de $97,8 \%$ de resíduos coletados. Já no Estado do Rio Grande do Sul esse índice é maior, passando para 99,5\%. Ainda com relação ao Estado $0,4 \%$ desse lixo é queimado ou enterrado na propriedade, $0 \%$ é jogado em terreno baldio ou logradouro ou jogado em rio, lago ou mar e 0,1\% tem 
outros destinos. No Plano Municipal de Gestão Integrada de Resíduos Sólidos, de Santa Cruz do Sul se observa que em 1991 foram coletados 59,3\% de resíduos sólidos urbanos, sendo que este número passa para 92,7\% no ano 2000 (PMGIRS, 2013, p. 35). O Plano Municipal de Gestão Integrada de Resíduos Sólidos de Santa Cruz do Sul visa à administração integrada dos resíduos por meio de um conjunto de ações normativas, operacionais, financeiras e de planejamento, levando em consideração aspectos referente à geração, segregação, acondicionamento, coleta, transporte, tratamento e disposição final dos resíduos, priorizando atender requisitos ambientais e de saúde pública (PMGIRS, 2013)

Os números são bem animadores, contudo, não condizem com o que se vê no cotidiano das cidades. É corrente ver resíduos, inclusive latinhas, garrafas pet ou sacola plástica jogados em terrenos baldios ou em rios, inclusive em áreas de reservas ambientais é comum haver restos de lixo de alguma natureza (seja uma latinha de bebida ou uma sacola plástica). Importante destacar que a degradação se manifesta na forma de externalidades que vão impor danos e custos sobre a sociedade, por isso é necessário desenvolver métodos para estimar esses custos e danos (Mueller, 2012).

Quando se fala em estilos de vida da sociedade também se questiona qual o modelo de desenvolvimento que esta mesma sociedade almeja para si, visto que há relação entre o mesmo e a forma como a sociedade produz seus produtos e serviços, como os consome e, principalmente, como os descarta, coleta, recicla, trata e dispõe e, portanto, não se pode simplesmente "jogar fora". Nesse sentido, a mídia (mídia aqui entendido como veículos de comunicação) tem um forte papel social na formação de opinião. Pode divulgar novos estilos de vida, sustentáveis ou não, visto que sua abrangência atinge diversas camadas sociais da população, tendo ainda certa influência no imaginário coletivo.

A intensidade com que a mensagem midiática atinge as pessoas é muito brutal e as fazem desejarem determinados estilos de vida que nem sempre são os que visam a sustentabilidade ambiental. O consumo exagerado faz com que cada vez mais se produza mais resíduos sem a preocupação com o descarte e o tratamento responsável. A mídia não deixa de ser um reflexo da própria sociedade competitiva, portanto fazse de suma importância, como afirma Zerbini (2006), saber enxergar a realidade complexa em que se vive. Nesse sentido é importante pensar que para a sobrevivência da sociedade e da própria economia é preciso assumir o compromisso com o futuro, cuidando do conjunto (Mueller, 2012). Consumir sem exageros, sabendo avaliar as consequências das escolhas. 
O consumo exagerado faz com que cada vez mais se produza mais resíduos sólidos urbanos sem a preocupação com o descarte e o tratamento responsável.

Enxergar o quanto estamos limitados em nossa capacidade de escolha crítica e consciente por causa da parcialidade intencional da mídia, evidenciada nos diversos veículos de comunicação, e da existência de um sistema autoritário e ditatorial - escamoteado na atmosfera falaciosa do discurso das grandes marcas e corporações em suas estratégias de marketing - de regras de conduta e desejos sociais de pertencimento (Zerbini, 2006, p.55).

Outra questão diz respeito às liberdades dos indivíduos. A visão liberal clássica adota o discurso de que as pessoas devem ter a liberdade de escolher seu estilo de vida desde que não prejudiquem as demais. Em um mundo globalizado e desigual, essa "fala" carece de mais elementos como a inclusão dos bens ambientais e das atitudes que evitem prejuízos para qualquer ser vivo, tanto para as atuais como para as futuras gerações. Os direitos e as responsabilidades ambientais são de todos e não apenas de uma parte da sociedade (Giddens, 2010), mas para ser responsável é preciso estar consciente de seus atos, quando mais uma vez, a educação deve se fazer presente. O que se percebe é muito mais um discurso vazio que traz certa notoriedade do que ações que realmente contribuam para um planeta mais sustentável ambientalmente.

Enfim, para que as mudanças possam ocorrer não basta querer mudar. É necessário estar aberto para as mudanças advindas desse processo que em diversas vezes podem vir de encontro aos hábitos cotidianos. É preciso ter ciência sabendo que essas ações também irão refletir no estilo de vida das pessoas, em especial, no que tange ao consumo. Todos (atores sociais e a própria sociedade) são responsáveis pelo que se tem hoje e pelo que se terá no futuro, em termos de produção, consumo, descarte e os impactos decorrentes dessa relação homem-natureza.

O mais difícil na equação capital versus recursos naturais é o equilíbrio dos interesses envolvidos. É inegável que o ser humano invadiu quase todos os sistemas da terra, envenenando extensamente o meio ambiente, tornando-se imprescindível uma solução para esta questão (Mueller, 2012). Assim, faz-se urgente uma atitude frente às situações ambientais que se apresentam na contemporaneidade. Resta saber se o ser humano irá conseguir, de fato, não só refletir, mas também agir a tempo para reverter às atuais mudanças climáticas (Giddens, 2010).

Desta forma, investir em processos de educação ambiental continuado desde cedo, tanto nas escolas quanto em casa, pode ser uma estratégia crucial para o consumo mais consciente, bem como para o descarte seletivo, coleta seletiva e a reciclagem de resíduos sólidos urbanos. Não apenas a educação em si, mas também considerar o conhecimento local e a realidade das populações (que moram ou 
trabalham) para constituir novos conhecimentos a respeito dos recursos naturais e sua capacidade de renovação, entendendo ainda que, embora o meio ambiente consiga se renovar, ele não o faz no mesmo tempo social com a rapidez com que o ser humano se apossa dos recursos naturais. Se tudo está dentro de um sistema (atores sociais com conhecimentos diversos e o meio ambiente) é crucial que haja um equilíbrio nesse complexo sistema para que ambos possam sobreviver. De outra forma, se os recursos naturais acabarem significa que a própria vida humana também irá se extinguir, pois ela não só depende como faz parte estando intrinsecamente relacionada ao meio ambiente.

A Lei no 12.305/2010, da Política Nacional de Resíduos Sólidos (PNRS, 2010) salienta a adoção de medidas em relação à não geração, redução, reutilização e reciclagem dos resíduos sólidos produzidos pela população (Brasil, 2010). Entre essas medidas se encontra a conscientização e a educação ambiental, a qual é entendida como "os processos por meio dos quais o indivíduo e a coletividade constroem valores sociais, conhecimentos, habilidades, atitudes e competências voltadas para a conservação do meio ambiente, essencial à qualidade de vida e sua sustentabilidade" (Brasil, 1999). Para dar efetividade à mesma, a educação ambiental, segundo a Política Nacional de Educação Ambiental - PNEA - refere-se às

ações e práticas educativas voltadas à sensibilização da coletividade sobre as questões ambientais e à sua organização e participação na defesa da qualidade do meio ambiente, devendo o Poder Público (Federal, Estadual e Municipal) [deve] incentivar a ampla participação das escolas, universidades, empresas e organizações nãogovernamentais na formulação e execução de programas e atividades vinculadas à educação ambiental não informal (PMSCS, 2013, p. 36).

Nesse sentido, sabedores de que o retorno virá em longo prazo o município de Santa Cruz do Sul tem buscado centrar seus esforços na educação ambiental, principalmente, nas escolas de ensino fundamental e médio. Investem em ações pontuais devido aos recursos financeiros limitados que possuem (Silveira, 2016). Sob esta perspectiva, percebe-se ainda a necessidade de que toda a sociedade deveria estar envolvida em um estilo de vida mais sustentável e, de modo igual, em uma prática educativa que preserva o meio ambiente com um todo. Destarte, torna-se essencial começar, mesmo que a passos lentos ou mesmo que com poucas ações específicas essas mudanças significativas em prol de um futuro com mais qualidade de vida para todos sem devastar o meio ambiente com um ritmo harmônico na relação homem-natureza. Mas para isso é preciso enxergar, inquietar-se e intervir para superar a crise ética que a humanidade está passando (Zerbini, 2006). É, portanto, uma questão de cidadania, e de percepção da necessidade de uma nova razão, de um 
novo modelo de desenvolvimento, para preservar os recursos naturais e zelar pelo bem da coletividade.

\section{Resíduos sólidos urbanos em Santa Cruz do Sul}

Dados do Governo Federal mostram que o setor de reciclagem movimenta aproximadamente $\mathrm{R} \$ 12$ bilhões/ano, perdendo $\mathrm{R} \$ 8$ bilhões anualmente por "[...] deixar de reciclar os resíduos que são encaminhados para aterros e lixões [...]". Em termos de percentuais, estima-se que a reciclagem de resíduos está presente em apenas $8 \%$ dos municípios brasileiros. Outro dado disponibilizado é o de que "[...] 99,9\% do material reciclável que vai para a indústria passa pelas mãos dos catadores - organizados e não organizados" (Brasil, 2012). O PMGIRS (PMSCS, 2013) menciona que a gestão dos resíduos sólidos é também uma questão social e que a participação dos catadores é um dos pontos mais visíveis desse aspecto da sociedade. Medida que vai ao encontro da inserção e a capacitação desses atores no processo da gestão dos resíduos sólidos, conforme Decreto 7.474/10 que regulamenta a Política Nacional de Resíduos Sólidos.

Em termos de tipos de materiais reciclados no país, o alumínio atinge o patamar $90 \%$, já o restante dos materiais varia entre $45 \%$ a 55\% (IBGE, 2010). Certamente o alto valor agregado no resíduo de embalagens à base de alumínio e o gasto nessa produção fazem com que o mercado do alumínio se destaque dos demais. Pode-se também colocar a mídia como um dos responsáveis por essa conscientização, favorecendo a reciclagem de materiais de alumínio. Quando se veicula reportagens sobre a reciclagem de resíduos sólidos a imagem de catadores coletando latinhas se torna um padrão na mídia. Esse resíduo é o que mais fornece retorno financeiro aos catadores. Nesse sentido, discutir-se-á, na sequência, a reciclagem de resíduos sólidos urbanos, em Santa Cruz do Sul-RS, no contexto do desenvolvimento local e regional.

O município de Santa Cruz do Sul está localizado no centro-leste do Estado do Rio Grande do Sul, Brasil, no centro das regiões dos Vales do Rio Pardo e Taquari, sendo a cidade polo dentre os 47 municípios integrantes dessas regiões (PMSCS, 2013, p. 25). Tem sua população estimada em 126.084 pessoas (IBGE, 2016), sendo que $89 \%$ vivem em áreas urbanas (IBGE, 2010), muito embora a área rural também receba os serviços de coleta de resíduos, mas não na mesma frequência da área urbana. De 2010 a 2016 a população santa-cruzense cresceu aproximadamente pouco mais de sete mil pessoas em cinco anos. Com este crescimento aumentou a geração de resíduos sólidos urbanos e a forma como o poder público local trabalha a coleta seletiva e a reciclagem desses resíduos. 
Segundo dados do Sistema Nacional de Informações sobre Saneamento (SNIS, 2016), em Santa Cruz do Sul a média de materiais recicláveis recuperados é de 61,7 toneladas por ano, sendo que 48,9 toneladas são de papeis e papelão recicláveis. Essa coleta seletiva é executada pela-Cooperativa de Catadores e Recicladores de Santa Cruz do Sul - COOMCAT, com parceria/apoio da Prefeitura Municipal. A Secretaria Municipal de Meio Ambiente, Saneamento e Sustentabilidade - SMMASS - de Santa Cruz do Sul, é o órgão de competência pela gestão dos resíduos sólidos urbanos, assim como todos os processos de gerenciamento dos resíduos sólidos passam pela Secretaria, envolvendo contratações, definição de sistema de coleta, tratamento, transporte e destinação, educação e fiscalização junto a Unidade Central de Fiscalização Externa - UCEFEX (Silveira, 2016).

Já a Conesul Serviços Ambientais tem sua responsabilidade no que se refere à coleta dos resíduos, destinação e transporte ao aterro sanitário, em Minas do LeãoRS. Ambas as prestadoras de serviços - COOMCAT e Conesul prestam conta para SMMASS. Segundo a Conesul (2016) sua atuação "[...] é atender a gestão total de resíduos no município". Entretanto, essa informação não está correta, pois a Conesul é uma prestadora de serviços tanto quanto a COOMCAT, não sendo a Cooperativa de Catadores e nem a SMMASS subordinadas à Conesul. Portanto, afirmar que a gestão total dos resíduos é unicamente de sua responsabilidade mostra que pelo menos em parte, os atores discordam entre si em relação aos papeis que desempenham na cadeia de coleta, reciclagem e destinação de resíduos sólidos. Essa discordância pode gerar problemas na coleta seletiva, bem como no andamento do processo de coleta, processamento, reciclagem e destino dos resíduos urbanos.

Silveira (2016) esclareceu que a Prefeitura é a gestora dos resíduos sólidos urbanos (domésticos e comerciais com característica de doméstico), sendo "parte dessa gestão feita por empresa privada e pela cooperativa, no caso a Conesul e a COOMCAT". Reforça-se, portanto, de que não se trata apenas de um ator na gestão dos resíduos sólidos, mas de um conjunto de atores no qual cada um tem sua responsabilidade. Quando um dos atores toma para si a incumbência de uma gestão sem de fato fazê-lo, trata-se de um mero discurso que tem outras intenções que não a veracidade de informações.

Ainda segundo Silveira (2016), o município tem o total de 36 bairros, sendo atendidos, no momento, com a coleta seletiva apenas nove bairros, ou seja, 33\% da população urbana. Não há um processo de reciclagem de resíduos sólidos propriamente, todavia o que existe é uma coleta seletiva solidária (CSS) que, por meio dos catadores, coleta os materiais recicláveis gerados nesses nove bairros diretos na 
fonte geradora. Após, esses materiais, triados e selecionados pelos catadores, são prensados, armazenados e comercializados. Ao realizar a CSS se está também a contribuir para geração de renda e empregos, através da cadeia de reciclagem.

Tudo que o ser humano consome ao ser produzido demandou algum tipo de recurso natural e ao enterrar resíduos recicláveis se está impedindo que esses recursos possam retornar ao ciclo produtivo. Nesse sentido, questiona-se sob a forma como a sociedade está crescendo economicamente e os danos irreparáveis que tem provocado no meio ambiente, bem como a forma com que a sociedade tem enfrentado os impactos ao meio ambiente. O processo atual de enterrar resíduos recicláveis gera mais bens produzidos e novos recursos naturais extraídos da natureza. É uma logística totalmente insustentável (Silveira, 2016). A importância tanto local quanto regional se encontra no desenvolvimento conjunto de fatores sociais, econômicos, ambientais e culturais, nos quais todos são corresponsáveis, inclusive os municípios adjacentes. Assim, o cuidado com os resíduos sólidos urbanos diz respeito a desenvolvimento local, bem como ao desenvolvimento regional.

De acordo com o portal online da Secretaria Municipal de Meio Ambiente, Saneamento e Sustentabilidade (SMMASS, 2015), de Santa Cruz do Sul, houve um mapeamento de 16 pontos de descarte irregular em 2015. Segundo o referido portal online, os resíduos foram jogados em locais inapropriados como terrenos baldios, praças, ruas, rios e outros, divergindo dos dados apresentados pelo IBGE, em 2010, em relação aos resíduos atirados nesses locais. Essa discordância de informações demonstra um retrato de uma realidade em determinado tempo, visto que a vida e as relações socioeconômicas são dinâmicas. Essa realidade é constantemente alterada, seja para melhor ou não.

Nesses destinos clandestinos mapeados, a prática de descarte irregular foi recorrente. Segundo dados da SMMASS (2015), o problema se tornou maior na periferia onde há "[...] falta de conscientização por parte dos moradores quando se trata de tirar de casa aquilo que para eles não tem mais serventia". Ao descartar os resíduos sólidos sem a preocupação com seu destino adequado se cria problemas ambientais e sociais maiores. "[...] No caso do descarte irregular de pneus há o risco de proliferação do mosquito da dengue e, no caso dos eletrônicos, a liberação de substâncias tóxicas como cádmio e arsênio que contaminam o lençol freático" (SMMASS, 2015). O simples "jogar fora" pode causar um impacto severo à natureza de forma que ela não consiga se recuperar novamente, visto que, a prática recorrente dessa "simples" ação já ocorre há muitas décadas. 
Assim, pode-se afirmar que a questão educacional se torna crucial também como uma estratégia de enfrentamento dos problemas relacionados à reciclagem dos resíduos sólidos urbanos. Cabe ressaltar que a educação, apesar de extremamente importante é um processo de longo prazo. Para obter resultados positivos nesse processo é preciso o enfrentamento das questões ambientais, como, por exemplo, as políticas públicas que inibam a degradação ambiental. Além disso, há o trabalho realizado pelas organizações que fazem a coleta seletiva desses resíduos. Esse é um resultado de médio prazo que possibilita minimizar os impactos ao meio ambiente. As diretrizes nacionais para o saneamento básico estabelecido pela Lei no 11.445/2007, permitiu que as prefeituras contratassem as organizações de catadores para o trabalho de coleta seletiva (BRASIL, 2012).

Em 1988 foi criada a Usina de Reciclagem e Compostagem no município de Santa Cruz do Sul e, em 2010, foi implantada a Cooperativa dos Catadores e Recicladores de Santa Cruz do Sul, a COOMCAT, antiga Associação Ecológica de Catadores de Materiais Recicláveis que trabalhava na administração da Usina Municipal de Reciclagem. Ficam sob sua responsabilidade a triagem, classificação e separação dos resíduos, sendo que a coleta convencional e a destinação final continuam sendo realizadas pela Conesul Soluções Ambientais, empresa privada contratada pela Prefeitura Municipal. De acordo com Ferreira (2010), quando a COOMCAT assumiu a usina, ela recebia aproximadamente 90 toneladas de lixo diariamente, sendo que apenas $8 \%$ dos resíduos eram reciclados. Para que o índice chegasse perto de $50 \%$ de material a ser reciclado foi implantada a coleta seletiva solidária.

Já segundo Silveira et al (2014), embora o processo de reciclagem e tratamento de resíduos sólidos urbanos em Santa Cruz do Sul tenha mais de 27 anos de atividade, somente a partir de 2010 é que o processo de coleta seletiva de resíduos sólidos se concretizou de fato. Percebe-se que no mesmo ano (em 2010) houve a aprovação da Política Nacional de Resíduos Sólidos (PNRS, 2010) que reconheceu as cooperativas dos catadores como potenciais fornecedores das empresas no sentido de viabilizar os fluxos reversos dos materiais recicláveis e a Lei Federal 12.305/2010, regulamentada pelo Decreto 7.404/2010, na qual foram iniciadas ações em conjunto com o governo, as entidades privadas e a sociedade civil, alertando que os resíduos sólidos são um problema de todas as pessoas.

Certamente essas duas leis aprovadas em 2010 impulsionaram e influenciaram o processo de reciclagem no município de Santa Cruz do Sul, mas não apenas a legislação foi suficiente. Se não fosse a atuação do Fórum de Ação pela Coleta Seletiva Solidária e Reciclagem em Santa Cruz do Sul - FACS, uma mobilização social com 
ampla representação da sociedade civil organizada, a qual teve início em 2009, a participação da COOMCAT como prestadora de serviços municipais estaria prejudicada. Posteriormente, tornou-se uma organização independente com o assessoramento do Movimento Nacional dos Catadores e Recicladores - MNCR e de projetos de extensão universitária (Silveira, Schimitz \& Santos, 2014). Em outra direção, pode-se ainda inferir que as mudanças somente ocorrem quando mediadas por alguma lei que impacte a sociedade ou favoreça os interesses de parte dos atores sociais, como é o caso da Lei n.o 7.405/2010, que instituiu o Programa Pró-Catador, que dispensa a contratação de cooperativas de catadores sem licitação como forma de atender não apenas às questões sanitárias, mas também a inclusão social.

De acordo com uma visita in loco realizada em novembro de 2016 na Usina de Reciclagem e Compostagem, de Santa Cruz do Sul, a Associação de Catadores e a Conesul Soluções Ambientais divergem quanto ao que é o não reciclado. Essa discordância gera certo desentendimento entre ambas as organizações, prejudicando mesmo que parcialmente a coleta, reciclagem e a destinação adequada. Na ocasião, um dos responsáveis por esse trabalho mencionou que é preciso o apoio da comunidade para que os resíduos sejam reciclados. Algumas dessas práticas dizem respeito à forma como os catadores e recicladores recebem os resíduos sólidos como, por exemplo, furar as embalagens longa vida ou lavar as embalagens de alumínio para que não fiquem restos de produto, causando um cheiro insuportável para quem faz o manejo dos resíduos sólidos urbanos e, algumas vezes, inviabilizando a própria reciclagem.

O fato de os resíduos chegarem aos catadores de forma incorreta causa problemas de saúde a esses profissionais que estão trabalhando em prol de uma sociedade melhor e em prol de uma melhor qualidade de vida para si. Demonstra ainda o descaso da própria sociedade com o destino do que descarta, sendo indiferente para com quem trabalha nessa atividade. Se a sociedade não mostra interesse, mobilizando-se em relação à reciclagem, esse processo não avançará, pois depende do envolvimento de todos. Precisa-se refletir se o que se quer é um planeta somente para a geração atual ou se é um planeta no qual as próximas gerações também irão aproveitar de suas belezas e recursos.

É uma questão de respeitar o outro, de entender que esta ação simples pode gerar um ambiente de trabalho com melhores condições aos catadores que, por sua vez, promovem um importante serviço à sociedade e ao meio ambiente. A sociedade é um sistema, no qual cada cidadão, ao fazer a sua parte, colabora consigo mesmo e com a vida no planeta. Se um dos elos desse sistema não cumprir a sua parte ou falhar 
de alguma forma, o sistema como um todo também falhará. Quando se trabalha em prol de uma melhor qualidade de vida, buscando a sustentabilidade ambiental também se está promovendo o desenvolvimento não apenas local, mas também regional, visto que os impactos ambientais não reconhecem fronteiras políticas.

Quanto ao destino dos resíduos sólidos, Silveira (2016) enfatizou que Santa Cruz do Sul não recebe RSU de nenhum outro município, pois cada um é responsável por sua gestão e logística de resíduos. "Geralmente a mesma empresa privada faz a coleta, transporte e destinação final dos resíduos sólidos. Uma realidade estabelecida por questões financeiras e de viabilidade técnica" (Silveira, 2016). Embora haja discussões sobre novas opções para a gestão dos RSU ainda não há nada concreto, pois se trata de um processo lento e demorado.

Treze municípios do Vale do Rio Pardo levam seus resíduos para o aterro em Minas do Leão-RS, apresentando uma articulação entre si, tendo como fio condutor as questões ambientais, embora cada qual viabilizando o transporte de forma independente dos demais municípios. Esses municípios são associados ao Consórcio Intermunicipal de Serviços do Vale do Rio Pardo - CISVALE - e destinam seus resíduos para a Companhia Rio-grandense de Valorização de Resíduos - CRVR, em Minas do Leão. "A legislação não conduz a aterro local ou regional, ela conduz à destinação ambientalmente correta e, no momento, este aterro é a melhor opção", sem esclarecer o motivo dessa opção e o quanto custa para o município essa tomada de decisão em detrimento de outras possibilidades (Silveira, 2016). Ao se organizarem desta forma, os municípios demonstram uma racionalidade econômica, que aparentemente se reveste de uma preocupação com um desenvolvimento regional para além do local. Por não ter um aterro de âmbito regional, demonstra-se que não há uma preocupação regional com a destinação dos RSU, estando cada município sozinho no que tange a esta questão. Possivelmente, se houvesse o compartilhamento dessas preocupações em termos regionais, poder-se-ia encontrar novas soluções para o problema que é comum aos municípios.

O resultado desses processos e aprendizagens na gestão de resíduos sólidos é um caminho próprio construído na sua maioria com a força intelectual e de trabalho local, com inclusão social, sem deixar de estarem articulados às outras escalas de gestão, na busca pela sustentabilidade social, econômica e ambiental. O empoderamento da população coparticipante/corresponsável e dos catadores organizados em cooperativas é de fundamental importância nesse processo, bem como a articulação entre as diferentes secretarias municipais e o gestor do consórcio público para que a conjunção de esforços resulte em efetividade na ação (Silveira \& 
Philippi, 2013). É importante trabalhar com a qualidade de vida no intuito de promover o desenvolvimento local e regional. Igualmente trabalhar as questões ambientais desde cedo, por meio de uma nova postura educacional, mostra-se uma estratégia promissora em longo prazo, assim como, o entendimento de que somos todos corresponsáveis pelo que a sociedade produz e descarta.

É importante refletir cada vez mais sobre a complexidade das questões ambientais, considerando que a área ambiental trabalha com probabilidades, pois não há como dar certeza de nada. A relação sociedade-natureza permeia por comportamentos complexos da sociedade, assim como as relações de poder no território na perspectiva da gestão ambiental e com a própria imprevisibilidade do meio ambiente. $\mathrm{Na}$ contemporaneidade, observam-se muitos discursos voltados à sustentabilidade ambiental, havendo poucas ou até mesmo a ausência de práticas mais sustentáveis. Essa é uma realidade que precisa mudar o mais rápido possível para que o impacto à vida humana não chegue ao ponto de extinção por suas próprias ações.

\section{Conclusão}

Quando o assunto é a área ambiental não há como ter certezas absolutas, tudo é uma questão de pensar a partir de probabilidades conforme a realidade de cada território e região. Interpretar o sistema ambiental significa ir à raiz do problema, evidenciar suas relações e encadear soluções que considerem as interdependências das relações do ser humano, já que não se vive isolado. No caso de Santa Cruz do Sul-RS, há uma divergência de interesses entre atores sociais no que se refere à coleta e destinação dos resíduos sólidos. Estas questões trazem à reflexão de como construir, no presente, um futuro mais sustentável, já que há tantas divergências em relação aos interesses dos diferentes grupos sociais. Percebem-se a existência de discursos sustentáveis, mas com ausência ou pouca ação de práticas desta natureza.

Quando se busca trabalhar de forma conjunta essas diferentes visões, percebese o quão complexa se torna as discussões ambientais e sociais. Torna-se cada vez mais urgente compreender o que está por detrás das informações que chegam aos cidadãos, quais os seus fluxos e quais relações emergem para que possam fazer escolhas mais conscientes e sustentáveis. Esta complexidade dos sistemas socioambientais é um grande desafio para a humanidade. Assim como Santa Cruz do Sul outros municípios têm esse mesmo enfrentamento de fazer com que seus atores conversem entre si com alteridade, em prol de uma questão que diz respeito a toda região, muito além do âmbito local. 
As articulações conjuntas entre os municípios são necessárias para um processo de desenvolvimento regional, demandando relações que extrapolam os territórios municipais. Juntos, os municípios se tornam mais fortes, conquistando melhor e mais rapidamente soluções para seus problemas em diversas esferas, incluindo a ambiental. Torna-se importante que os governos municipais percebam que ao atuarem conjuntamente não vão perder o seu "poder". Muito pelo contrário, estarão se fortalecendo ao desenvolverem estratégias de coleta, tratamento e destinação de seus resíduos sólidos em parceria com outros municípios para que suas experiências possam resultar em um conjunto de ações que busquem a qualidade de vida de toda a região. É necessário estar aberto para a possibilidade de implantação de um aterro de rejeitos regional, de uma usina de compostagem regional, além da coleta seletiva solidária regionalizada, com todos os requisitos técnicos atendidos, como também o gerenciamento continuado por pessoas qualificadas para tal, conforme suas habilidades profissionais.

A coleta seletiva, a reciclagem de resíduos sólidos e a conscientização ambiental são algumas das estratégias locais para a redução de aterros sanitários controlados ou não. Torna-se igualmente essencial que os municípios dialoguem com os demais, em busca de soluções que possam ser compartilhadas entre si, visando um desenvolvimento regional voltado a coletividade e não a individualidade municipal. São importantes desafios que a sociedade precisa enfrentar o mais breve possível, sem deixar para amanhã (futuro).

O caso de Santa Cruz do Sul ainda não é o modelo perfeito de coleta seletiva, reciclagem, tratamento de resíduos sólidos e de trabalho em prol da região. Todavia, é um começo, em que seus atores e a própria sociedade precisam focar suas preocupações em prol de um desenvolvimento regional que leve em conta a diversidade da própria região e os problemas de cada município. Sem começar por algum ponto, cai-se na comodidade de deixar sempre para o outro fazer ações que podem ser feitas agora, evitando realidades que talvez não tenham mais como serem recuperadas ambientalmente.

Entre as limitações do estudo está a falta de retorno do questionário enviado à Conesul, bem como a pesquisa estar centrada em apenas um município, podendo estender-se a uma região.

A contribuição para estudos posteriores parte da abrangência da pesquisa a outros municípios da região central do Rio Grande do Sul, de forma a gerar uma análise ampla sobre a coleta de resíduos sólidos urbanos. Destaca-se que este é um grande problema da sociedade e que somente com o envolvimento e compromisso de todos 
os atores sociais é que se conseguirá encontrar caminhos sustentáveis para sua resolução.

\section{Referências}

BRASIL (2007). Lei n. ${ }^{\circ} 11.445$, de 5 de janeiro de 2007. Estabelece as diretrizes nacionais para o saneamento básico. http://www.planalto.gov.br/ccivil_03/_ato20072010/2007/lei/l11445.htm. Acesso em jan. 2016.

BRASIL (2010). Lei n. 012.305 de 02 de agosto de 2010. Institui a Política Nacional de Resíduos Sólidos. http://www.planalto.gov.br/ccivil_03/_ato20072010/2010/lei/l12305.htm. Acesso em jan. 2017.

BRASIL (1999). Lei n. 09.795 de 27 de abril de 1999. Dispõe sobre a educação ambiental e institui a Política Nacional de Educação Ambiental. http://www.planalto.gov.br/ccivil_03/leis/L9795.htm. Acesso em jan. 2017.

BRASIL (2010). Decreto n. 07.474 de 23 de dezembro de 2010. Regulamenta a Lei $12.305 / 2010$. 2010/2010/decreto/d7404.htm. Acesso em jan. 2017.

BRASIL (2010). Decreto n. 07.405 de 23 de dezembro de 2010 - Instituiu o Programa Pró-Catador, denominou de Comitê Interministerial para Inclusão Social de Catadores de Materiais Reutilizáveis e Recicláveis. http://www.mncr.org.br/biblioteca/legislacao/leis-e-decretos-federais>. Acesso em jan. 2017.

BRASIL (2016). Portal Brasil. Site institucional do Governo Federal. http://www.brasil.gov.br/meio-ambiente/2012/04/reciclagem-atinge-apenas-8-porcentodos-municipios-brasileiros. Post abril, 2012. Acesso em jan. 2016.

CISVALE (2016). Consórcio intermunicipal de serviços do Vale do Rio Pardo. Site Institucional. http://cisvalerp.com.br. Acesso em: fev. 2016.

COOMCAT (2015). Coleta seletiva solidária, Santa Cruz do Sul, 2015. 1 folder. Apoio Secretaria de meio ambiente do município de Santa Cruz do Sul. Material elaborado para o projeto Transformando lixo em solidariedade.

CNVR (2016). Companhia Rio-grandense de Valorização de Resíduos. Site Institucional. http://www.crvr.com.br/. Acesso em: fev. 2016.

IBGE (2010). Instituto Brasileiro de Geografia e Estatística. Indicadores do Desenvolvimento Sustentável. In: Estudos e Pesquisas: Informação geográfica, N. 7, Brasil, Rio de Janeiro, 2010.: http://www.ibge.gov.br/home/geociencias/recursosnaturais/ids/ids2010.pdf. Acesso em: jan. 2016.

IBGE (2016). Site institucional do Instituto Brasileiro de Geografia e Estatística. http://cidades.ibge.gov.br/xtras/perfil.php?lang=\&codmun $=431680 \&$ search $=||$ infogr\%E1 ficos:-informa\%E7\%F5es-completas. Acesso em: jan. 2016.

FERREIRA, R. B. (2010). Usina de lixo é gerida por catadores. Jornal Gazeta do Sul, Portal Gaz, Santa Cruz do Sul, 07 set. 2010. http://www.grupogaz.com.br/gazetadosul/noticia/240970usina_de_lixo_e_gerida_por_catadores/edicao:2010-09-07.html. Acesso em jan. 2016. 
FIGUEIREDO, P. J. M. (1994). A Sociedade do Lixo: os resíduos, a questão energética e a crise ambiental. Piracicaba/SP: UNIMEP.

GIDDENS, A. (2010). Retorno ao Planejamento? In: A política da mudança climática. Rio de Janeiro: Zahar, p. 120-163.

LEONARD, A. (2011). A História das Coisas: da natureza ao lixo, o que acontece com tudo o que consumimos. Rio de Janeiro: Zahar.

MUELLER, C. C. (2012). Os economistas e as relações entre o sistema econômico e o meio ambiente. Brasília: Editora Universidade de Brasília.

NOVO, M. V. (1997). El Análisis de los problemas ambientales: modelos y metodología. In: NOVO, M. V. \& LARA, RAMÓN T. Medio Ambiente y Educación Ambiental. Madrid: UNESCO/Fundación Universidad-Empresa de Madrid, p.19-59.

PERES, R. B.; CHIQUITO, E. A. (2012) Ordenamento Territorial, Meio Ambiente e Desenvolvimento Regional. In: Revista Brasileira de Estudos Urbanos e Regionais. 14(2), p.71-86.

http://unuhospedagem.com.br/revista/rbeur/index.php/rbeur/article/view/4102/4000>. Acesso em: set. 2015.

PNRS (2010). Política Nacional de Resíduos Sólidos, Lei no 12.305, de 2 de agosto de 2010. Institui a Política Nacional de Resíduos Sólidos; altera a Lei no 9.605, de 12 de fevereiro de 1998; e dá outras providências.

PMSCS (2013). Prefeitura Municipal de Santa Cruz do Sul. Plano Municipal de Gestão Integrada de Resíduos Sólidos. Relatório de Dezembro de 2013. http://santacruz.rs.gov.br. Acesso em: fev. 2016.

RIBEIRO, W. A. (2012). A relação entre os marcos regulatórios de saneamento básico e dos resíduos sólidos. In: JARDIM, Arnaldo; YOSHIDA, Consuelo; MACHADO FILHO, José V. (Org.). Política Nacional, Gestão e Gerenciamento de Resíduos Sólidos. Baueri/SP, Monole, 2012, p. 541-560.

RISSATO, D., SANTOS, L. S., \& NAZZARI, R. K. (2010). A gestão de resíduos sólidos urbanos: um relato sobre a experiência do município de Cascavel no período de 1990 a 2007. Revista Capital Científico Eletrônica, 8(1), p. 23-36.

Silva, c. I., Biernaski, I. (2018). Planejamento e Gestão de Resíduos Sólidos Urbanos: Um Estudo de Caso na Região Metropolitana de Belo Horizonte à Luz da PNRS. Gestão \& Regionalidade, 34(101), p. 184-199.

SILVEIRA, D. J. (2016). Departamento de Controle e Qualidade Ambiental de Santa Cruz do Sul. Entrevista concedida a Giovana Goretti Feijó de Almeida, em 16 fevereiro de 2016.

SILVEIRA, R. C. E.; MORAES, J. A. R.; TURCATTO, C. B.; BOUVIE, L. (2014). Tecnologias e Modelos de Gestão de Resíduos Sólidos no Município de Santa Cruz do Sul. Santa Cruz do Sul-RS, Revista Ágora, 16, p. 156-184.

SILVEIRA, R. C. E.; SCHIMITZ, J. A. K.; SANTOS, W. Go. (2014). Avanços e Retrocessos do Fórum de Ação pela Coleta Seletiva Solidária e Reciclagem em Santa Cruz do Sul - FACS. Anais do IX Simpósio Internacional de Qualidade Ambiental - Energia e Ambiente. Porto Alegre: ABES-RS. 
SILVEIRA, R. C. E.; PHILIPPI, L. S. (2013). Gestão Consorciada de Resíduos Sólidos em Municípios de Pequeno Porte no Sul do Brasil. Anais do $27^{\circ}$ Congresso Brasileiro de Engenharia Sanitária e Ambiental. Goiânia: ABES.

SMMASS (2015). Secretaria de meio ambiente do município de Santa Cruz do Sul. Site institucional. Abril,http://www.santacruz.rs.gov.br/noticias/806/secretaria-de-meioambiente-mapeia-16-pontos-de-descarte-irregular. Acesso em: jan. 2016.

SNIS (2016). Sistema Nacional de Informações sobre Saneamento. www.snis.gov.br. Acesso em fev. 2016.

ZERBINI, F. M. (2006). Modernidade e Crise Socioambiental. In: CINQUETTI, H.a C. S.; LOGAREZZI, A. Consumo e Resíduo: Fundamentos para o trabalho educativo. São Carlos/SP: EdUFSCar, p.43-57. 